\title{
BIOCHEMICAL EFFECT OF SOME MEDICINAL HERBS ON INDUCED HEPATOTOXICITY IN RAT
}

\author{
Tarek Kamal ${ }^{1)}$, Mustafa Shukry ${ }^{3)}$, Azza M. Elkattawy ${ }^{1)}$, SamyGomaa ${ }^{2}$, \\ Fatma Samir Elassal $^{1)}$, Nagwan El- Habashi ${ }^{4)}$ \\ ${ }^{1)}$ Department of Biochemistry, Faculty of Veterinary Medicine, Kafr El-Sheikh \\ University, Kafr El-Sheikh 54363, Egypt \\ ${ }^{2)}$ Department of Virology, Faculty of Veterinary Medicine, Kafr El-Sheikh University, \\ Kafr El-Sheikh, Egypt. \\ ${ }^{3)}$ Department of Physiology, Faculty of Veterinary Medicine, Kafr El-Sheikh University, \\ Kafr El-Sheikh, Egypt. \\ ${ }^{4)}$ Department of Veterinary Pathology, Faculty of Veterinary Medicine, Kafr El-Sheikh \\ University, Kafr El-Sheikh, Egypt.
}

\begin{abstract}
This study was planned to clarify the biochemical effects of the ginger on CCl4-induced acute hepatotoxicity and its comparison with garlic and combination between ginger and garlic through the determination of the following parameters in the blood and liver tissues of albino rats liver function test. The effect of ginger and garlic against CCLA was estimated by using white albino rats (150-200 g), which divided into 5 groups of 15 rats. The result showed that CCl4 increase GGT, AST and ALT enzymatic activities, while rats received ginger and / or garlic, their liver function parameters were restored to normal levels and the best result was that group received ginger and garlic after CCL4 injection.
\end{abstract}

Key words: CCL4, hepatotoxicity, ginger and garlic 


\section{INTRODUCTION}

Liver damage is the irregular function of the liver; with mitochondrial dysfunction reported as one of the major mechanism of drugs induce hepatotoxicity. By severely altering mitochondrial function in the liver, drugs can induce hepatic necrosis, causing cystolytic hepatitis, and can progress into liver failure (Jain and Singhai, 2010). Carbon tetrachloride $\left(\mathrm{CCl}_{4}\right)$ is a potent hepatotoxin producing centrilobular hepatic necrosis that causes liver injury, depends on a toxic agent that has to be metabolized by the liver NAPDH- cytochrome P450 enzyme system to a highly reactive intermediate (Ha et al., 2005).

Ginger (Zingiber officinale) belongs to Zingiberaceae family. It is one of the most important exogenous antioxidants that, is used for prophylaxis and treatment of various diseases caused by free radicals ( $\boldsymbol{E} \boldsymbol{l}$ Shemy et al., 2011). Garlic is a perennial plant originally from central Asia but now cultivated in the worldwide (Adejoke and Olakunle, 2012). It has a wide range of uses topmost being antioxidant properties (Borrelli et al., 2007). Ginger, garlic and a combination of ginger and garlic have been found to be useful in the prevention of severe hepatic injuries caused by a single dose of $\mathrm{CCl}_{4}$ in rats (Patrick-Iwuanyanwu et al., 2007). Our study investigated the effect of ginger and garlic as a supplement on hepatic drug-metabolizing CYP enzymes and whether it has a protective effect against CCL4 using white albino rats as experimental model. 


\section{MATERIALS AND METHODS}

The present study was carried out on 75 female albino rats of 150$200 \mathrm{gm}$ average body weight. The rats were divided into equal five groups of 15 rats each as the following Group 1: were given normal feed. The groups from 2 to 5 groups (60 rats) were intraperitoneally injected with $1 \mathrm{ml} / \mathrm{kg}$ CCL4 (single dose) (Kazeem et al., 2011). Group 2: left without treatment to the end of the experiment. Group 3: treated with Ginger extract orally with a single daily dose $250 \mathrm{mg} / \mathrm{kg}$ b.wt (Mohamed Atif and Ahmed, 2013). Group 4: treated with Garlic extract at dose 200 $\mathrm{mg} / \mathrm{kg}$ of body weight (Attalla et al., 2012). Group 5: treated with Ginger extract orally with a single daily dose $250 \mathrm{mg} / \mathrm{kg}$ b.wt plus Garlic extract at dose $200 \mathrm{mg} / \mathrm{kg}$ of body weight. Samples were collected after 72 hours, 2weeks and 4weeks from CCL4 injection, 5 rats were randomly chosen from each group for collection of blood and tissue samples.

Medicinal herbs: Ginger (Zingiberofficinale): ginger (GINGER, MEPACO-MEDIFOOD, Egypt) ginger extract orally with a single daily dose $250 \mathrm{mg} / \mathrm{kg}$ b.wt. (Mohamed Atif, 2013) and Garlic (Allium sativum): garlic (TOMEX, ATOS Pharma, Egypt) at dose $200 \mathrm{mg} /$ kg b.wt. (Attalla et al.,2012)

-Biochemical markers:Liver marker enzyme: AST, ALT and GGT. Their activities were measured colorimetrically using the method described by Reitman, and Frankel, 1957.

-Histopathological examination of animal livers: After necropsy, sections of the liver were dehydrated and embedded in paraffin wax by routine methods. They were then sectioned at $3 \mu \mathrm{m}$, stained with haematoxylin and eosin (HE), and examined by light microscopy. 


\section{RESULTS}

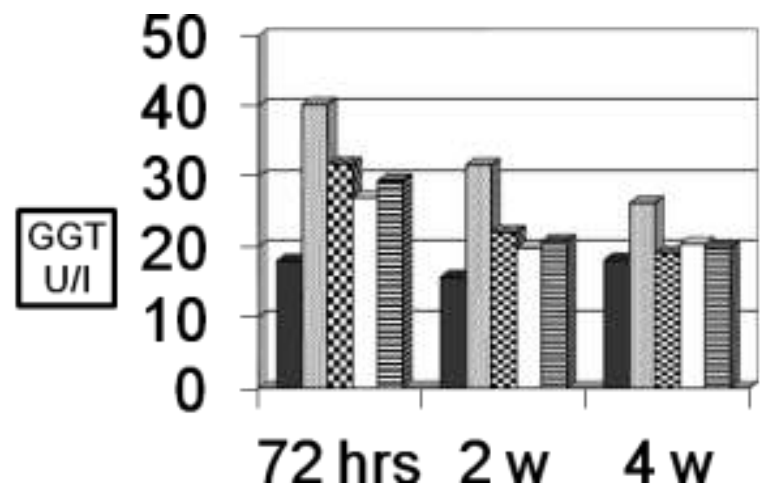

-Control negative
口control toxic
घinger
$\square$ Garlic
a Ginger + Garlic

\begin{tabular}{|c||c||c||c||}
\hline & 72 hours & 2 weeks & 4 weeks \\
\hline \hline Control negative & $18.03 \pm 1.89^{\mathrm{c} \mathrm{A}}$ & $15.75 \pm 2.56^{\mathrm{c} \mathrm{A}}$ & $18.17 \pm 2.85^{\mathrm{b} \mathrm{A}}$ \\
\cline { 2 - 4 } & $40.25 \pm 2.49^{\mathrm{a} \mathrm{A}}$ & $31.61 \pm 3.60^{\mathrm{a} \mathrm{B}}$ & $26.22 \pm 2.09^{\mathrm{a} \mathrm{B}}$ \\
\cline { 2 - 4 } Control toxic & $31.80 \pm 3.96^{\mathrm{b} \mathrm{A}}$ & $22.09 \pm 4.31^{\mathrm{b} \mathrm{B}}$ & $19.13 \pm 2.86^{\mathrm{b} \mathrm{B}}$ \\
\hline Ginger & $27.03 \pm 2.40^{\mathrm{b} \mathrm{A}}$ & $19.88 \pm 3.51^{\mathrm{bc} \mathrm{B}}$ & $20.45 \pm 5.35^{\mathrm{ab} \mathrm{B}}$ \\
\hline Garlic & $29.39 \pm 5.04^{\mathrm{b} \mathrm{A}}$ & $20.79 \pm 2.79^{\mathrm{bc} \mathrm{B}}$ & $19.85 \pm 3.02^{\mathrm{b} \mathrm{B}}$ \\
\hline Ginger plus Garlic & & &
\end{tabular}

Table(1)and Fig.(1): shows the Effect of Ginger, Garlic and their combination on serum $\gamma$-Glutamyltransferase $(\gamma \mathrm{GT})$ activity $(\mathrm{U} / \mathrm{l})$ in albino rats intoxicated with carbon tetrachloride.

It is clearly observed from the present study that the mean value of GGT activity were $18.03 \pm 1.89,15.75 \pm 2.56$ and $18.17 \pm 2.85 \mathrm{U} / \mathrm{I}$ in the control negative group and 40.25 $\pm 2.49,31.61 \pm 3.60$ and 26.22 $\pm 2.09 \mathrm{U} / \mathrm{I}$ in the control toxic group. The mean values in ginger treated group were $31.80 \pm 3.96,22.09 \pm 4.31$ and $19.13 \pm 2.86 \mathrm{U} / \mathrm{I}$ and $27.03 \pm 2.40,19.88 \pm 3.51$ and $20.45 \pm 5.35 \mathrm{U} / \mathrm{I}$ in the garlic treated group, while the mean values in the ginger \& garlic treated group were $29.39 \pm 5.04,20.79 \pm 2.79$ and $19.85 \pm 3.02 \mathrm{U} / \mathrm{I}$ at the 72 hours, 2 weeks and 4 weeks post experiment respectively. 


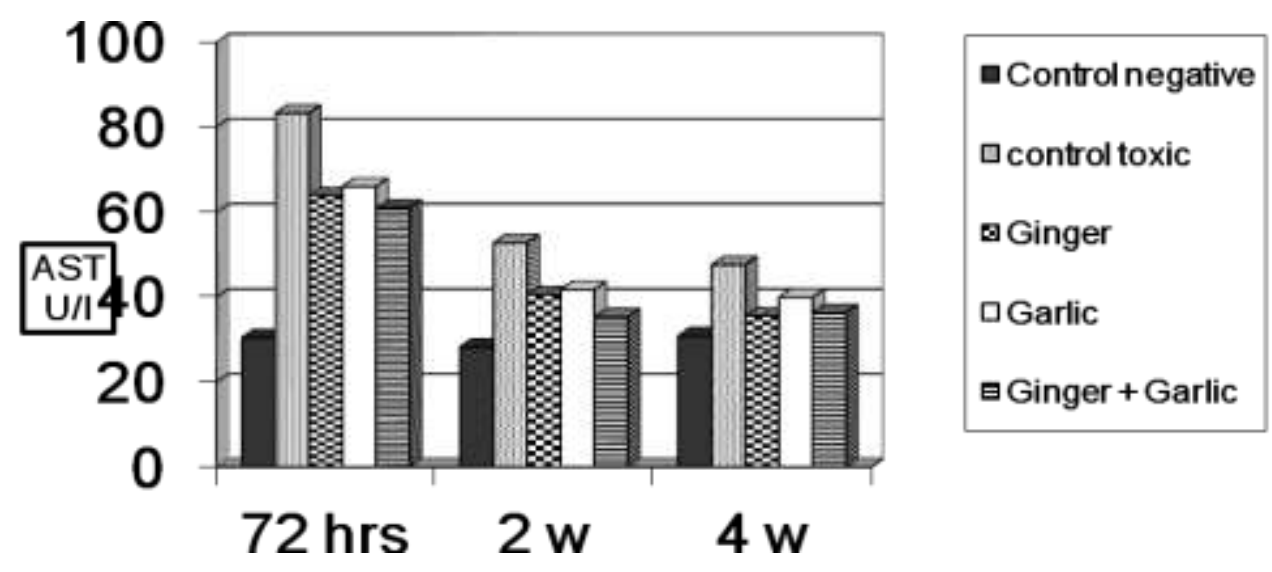

\begin{tabular}{|c||c||c||c||}
\hline & 72 hours & 2 weeks & 4 weeks \\
\hline \hline Control negative & $30.38 \pm 3.68^{\mathrm{c} \mathrm{A}}$ & $28.20 \pm 4.28^{\mathrm{d} \mathrm{A}}$ & $30.84 \pm 5.17^{\mathrm{c} \mathrm{A}}$ \\
\cline { 2 - 4 } & $83.24 \pm 9.36^{\mathrm{a} \mathrm{A}}$ & $52.74 \pm 7.48^{\mathrm{a} \mathrm{B}}$ & $47.58 \pm 6.33^{\mathrm{a} \mathrm{B}}$ \\
\cline { 2 - 4 } Control toxic & $63.82 \pm 6.36^{\mathrm{b} \mathrm{A}}$ & $40.52 \pm 6.98^{\mathrm{bc} \mathrm{B}}$ & $35.50 \pm 4.94^{\mathrm{bc} \mathrm{B}}$ \\
\hline Ginger & $65.98 \pm 6.18^{\mathrm{b} \mathrm{A}}$ & $41.70 \pm 3.48^{\mathrm{b} \mathrm{B}}$ & $39.92 \pm 5.60^{\mathrm{b} \mathrm{B}}$ \\
\hline Garlic & $60.86 \pm 6.28^{\mathrm{b} \mathrm{A}}$ & $35.32 \pm 3.99^{\mathrm{c} \mathrm{B}}$ & $36.34 \pm 3.29^{\mathrm{bc} \mathrm{B}}$ \\
\hline Ginger plus Garlic & & &
\end{tabular}

Table(2)and Fig.(2): shows the Effect of Ginger, Garlic and their combination on serum aspartate aminotransferase (AST) (GOT) activity (U/l) in albino rats intoxicated with carbon tetrachloride

It is clearly observed from the present study that the mean value of AST activity were $30.38 \pm 3.68,28.20 \pm 4.28$ and $30.84 \pm 5.17 \mathrm{U} / \mathrm{I}$ in the control negative group and 83.24 $\pm 9.36,52.74 \pm 7.48$ and 47.58 $\pm 6.33 \mathrm{U} / \mathrm{I}$ in the control toxic group. The mean values in ginger treated group were $63.82 \pm 6.36,40.52 \pm 6.98$ and $35.50 \pm 4.94 \mathrm{U} / \mathrm{I}$ and 65.98 $\pm 6.18,41.70 \pm 3.48$ and $39.92 \pm 5.60 \mathrm{U} / \mathrm{I}$ in the garlic treated group, while the mean values in the ginger \& garlic treated group were $60.86 \pm$ $6.28,35.32 \pm 3.99$ and $36.34 \pm 3.29 \mathrm{U} / \mathrm{I}$ at the 72 hours, 2 weeks and 4 weeks post experiment respectively. 
Tarek Kamal et., al.

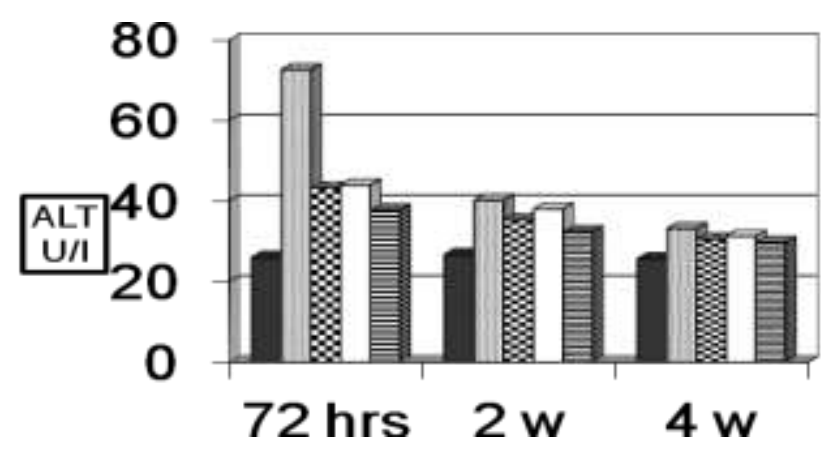

$\square$ Control negative
$\square$ control toxic
$\square$ Ginger
$\square$ Garlic
घGinger + Garlic

\begin{tabular}{|c||c||c||c||}
\hline & $\mathbf{7 2}$ hours & 2 weeks & 4 weeks \\
\hline \hline Control negative & $25.98 \pm 4.60^{\mathrm{d} \mathrm{A}}$ & $26.68 \pm 2.29^{\mathrm{b} \mathrm{A}}$ & $25.62 \pm 2.70^{\mathrm{b} \mathrm{A}}$ \\
\hline Control toxic & $72.52 \pm 5.82^{\mathrm{a} \mathrm{A}}$ & $40.16 \pm 5.35^{\mathrm{a} \mathrm{B}}$ & $33.12 \pm 3.23^{\mathrm{a} \mathrm{C}}$ \\
\cline { 2 - 4 } & $43.14 \pm 4.02^{\mathrm{bc} \mathrm{A}}$ & $35.26 \pm 3.58^{\mathrm{ab} \mathrm{B}}$ & $30.44 \pm 4.76^{\mathrm{ab} \mathrm{B}}$ \\
\hline Ginger & $43.90 \pm 6.32^{\mathrm{b} \mathrm{A}}$ & $37.96 \pm 2.76^{\mathrm{ab} \mathrm{A}}$ & $31.24 \pm 5.15^{\mathrm{ab} \mathrm{B}}$ \\
\hline Garlic & $37.66 \pm 5.51^{\mathrm{c} \mathrm{A}}$ & $32.30 \pm 8.80^{\mathrm{b} \mathrm{A}}$ & $29.66 \pm 5.10^{\mathrm{ab} \mathrm{B}}$ \\
\hline Ginger plus Garlic & & &
\end{tabular}

Table(3)and Fig.(3): shows the Effect of Ginger, Garlic and their combination on serum alanine aminotransferase (ALT) (GPT) activity (U/l) in albino rats intoxicated with carbon tetrachloride

It was observed from the present study that the mean value of serum alanine aminotransferase activity were $25.98 \pm 4.60,26.68 \pm$ 2.29 and $25.62 \pm 2.70 \mathrm{U} / \mathrm{I}$ in the control negative group, and $72.52 \pm$ $5.82,40.16 \pm 5.35$ and $33.12 \pm 3.23 \mathrm{U} / \mathrm{I}$ in the control toxic group. Concerning the ginger treated group the mean values were $43.14 \pm 4.02$, $35.26 \pm 3.58$ and $30.44 \pm 4.76 \mathrm{U} / \mathrm{I}$ and $43.90 \pm 6.32,37.96 \pm 2.76$ and $31.24 \pm 5.15 \mathrm{U} / \mathrm{I}$ in the garlic treated group, where in ginger \& garlic treated group the mean values were $37.66 \pm 5.51,32.30 \pm 8.80$ and $29.66 \pm 5.10 \mathrm{U} / \mathrm{I}$ in the at the 72 hours, 2 weeks and 4 weeks post experiment respectively. 


\section{Histopathology Results:}

Group (1) (control group): No detectable pathological changes were observed in the liver after 72 hrs, 2 weeks and 4 weeks (Fig.1).

Group (2) (CCL4 treated group): $72 \mathrm{hrs}$ after CCL4 injection, the liver showed focal fatty change as well as focal central sinusoidal cell dilatation, marked central congestion along with portal mononuclear cells infiltrations. In addition to the previously mentioned lesions, focal sinusoidal cell activation, areas of hemorrhages as well as mild focal hepatic cell necrosis were observed in few cases. After 2 weeks of CCL4 injection, the liver showed diffuse mixed fatty change (Fig. 2) and hydropic degeneration, portal mononuclear cells infiltrations. Focal apoptosis, marked central congestion as well as focal hepatic cell necrosis (Fig.3) infiltrated with mononuclear cells which tend to be multiple in one case. After 4 weeks of CCL4 injection, the liver was almost normal except mild congestion of the central vein and blood sinusoids, mild sinusoidal cell activation and focal sinusoidal dilatation and mild portal mononuclear cells infiltrations were observed.

Group (3) (Ginger received group): $72 \mathrm{hrs}$ after CCL4 injection, the liver was almost normal except mild focal hydropic degeneration, mild to moderate sinusoidal cell activation, focal sinusoidal dilatation (Fig.4), very mild congestion, mild portal mononuclear cells infiltrations were observed. Fatty change was not observed in any cases. After 2 weeks of CCL4 injection, the liver showed very mild congestion, moderate sinusoidal cell activation, moderate portal mononuclear cells infiltrations were detected in two cases, however, most of the cases showed changes previously mentioned in CCL4 treated group and in the same degree where diffuse mixed fatty change and hydropic degeneration as well as mononuclear cell infiltrations, sinusoidal cell activation and hepatic cell necrosis(Fig.5) or apoptosis were observed in most of the cases. After 4 weeks of CCL4 injection, the liver was almost normal except focal fatty change and focal sinusoidal cell activation and focal sinusoidal dilatation in most of the cases however, severe fatty change or mixed fatty change and hydropic degeneration were observed in some cases. 
Group (4) (Garlic received group): $72 \mathrm{hrs}$ after CCL4 injection, the liver was almost normal (Fig.6) except very mild focal hydropic degeneration, very mild congestion, mild sinusoidal dilatation, moderate sinusoidal cell activation and focal mononuclear cells infiltrations were detected in most of the cases. Fatty change was not observed in any cases. After 2 weeks of CCL4 injection, the liver was normal in few cases and only mild hydropic degeneration, moderate sinusoidal cell activation, mild congestion and marked mononuclear cells infiltrations. In the other cases, severe pathological changes including diffuse mixed fatty change and hydropic degeneration or severe fatty change as well as sinusoidal cell activation, mononuclear cells infiltrations and hepatic cell necrosis of the same degree as CCL4 treated group were observed. After 4 weeks of CCL4 injection, the liver was almost normal except very mild congestion, mild sinusoidal dilatation, mild sinusoidal cell activation and focal mononuclear cells infiltrations. In some cases, moderate mixed fatty change and hydropic degeneration or very mild hydropic degeneration and focal hepatic necrosis were observed.

Group (5) (Ginger and garlic received group): 72 hrs after CCL4 injection, the liver was almost normal except very mild congestion, mild sinusoidal dilatation, mild sinusoidal cell activation (Fig.7) and focal very mild fatty change were observed. However, few cases were almost completely normal as control. After 2 weeks of CCL4 injection, mild sinusoidal dilatation and mild sinusoidal cell activation, mild congestion as well as mild hydropic degeneration (Fig.8) in most of the cases, however in one case diffuse mixed fatty change and hydropic degeneration, hepatic cell necrosis, mononuclear cells infiltrations of the same degree as CCL4 treated group were observed. After 4 weeks of CCL4 injection, moderate vacuolation of fatty change and hydropic degeneration, hepatic cell necrosis, mononuclear cells infiltrations and sinusoidal dilatation were observed in most of the cases. 
Biochemical Effect Of Some Medicinal Herbs On ...

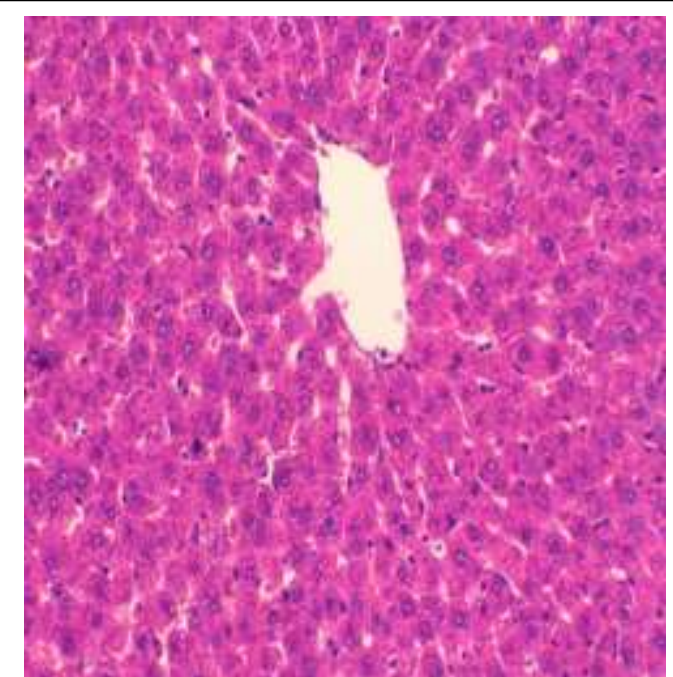

Fig. (1): control group, the liver showing normal lobular architecture with central vein and radiating hepatic cell cords. H\&E. X 20.

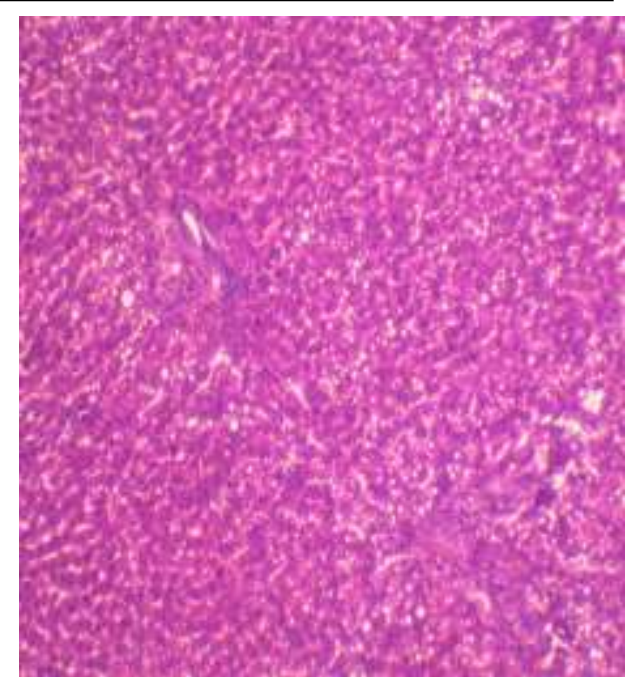

Fig. (2): CCL4 treated group, the liver showing fatty change. H\&E. X 10.

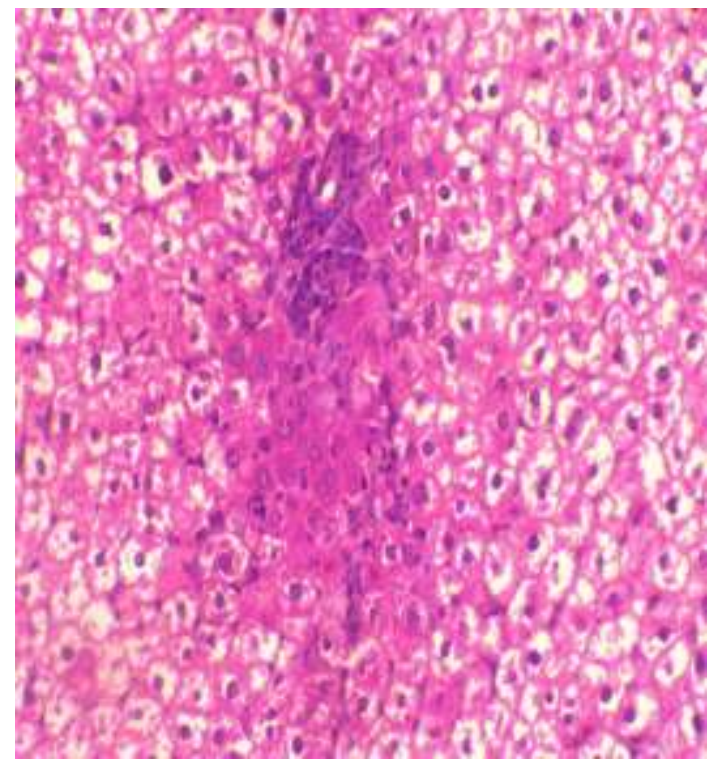

Fig (3): CCL4 treated group, the liver showing fatty change along with focal area of hepatic cell necrosis infiltrated with mononuclear cells. H\&E. X 20.

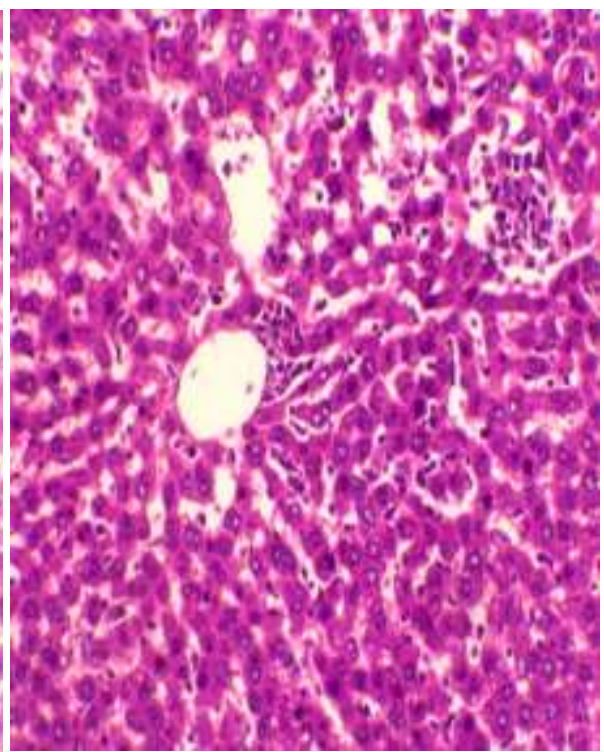

Fig. (4): Ginger received group, the liver showing sinusoidal cell dilatation and mild sinusoidal cell activation. H\&E. X 20.

Kafrelsheikh Vet. Med. J. Vol. 12 No. 2 (2014) 
Tarek Kamal et., al.

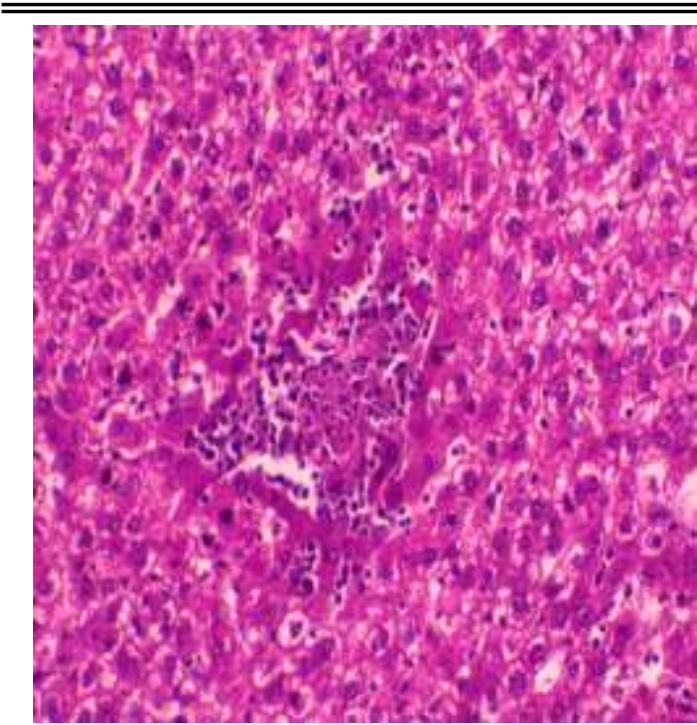

Fig. (5): Ginger received group, the liver showing vacuolation of hepatocytes along with focal area of hepatic cell necrosis infiltrated with mononuclear cells. H\&E. X 20.

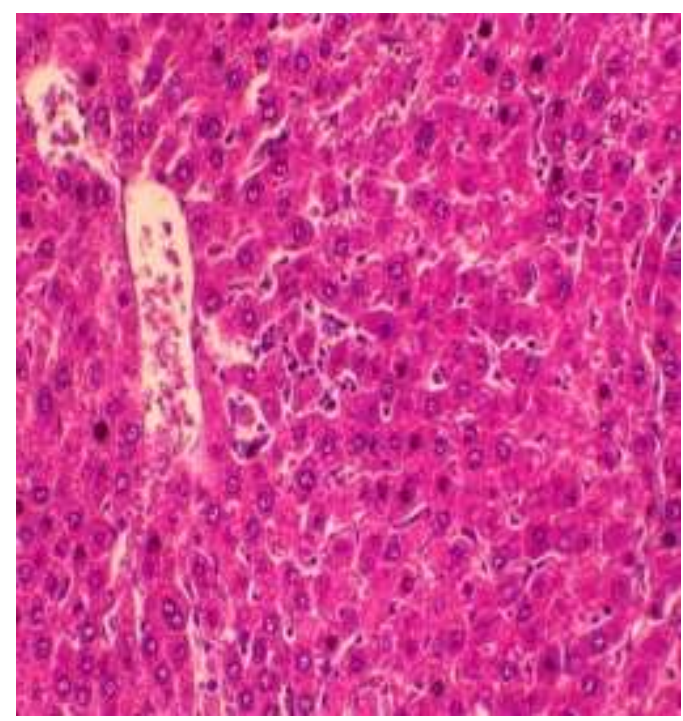

Fig.(7): Ginger and garlic received group, the liver showing mild congestion, mild sinusoidal dilatation, mild sinusoidal cell activation $\mathrm{H} \& \mathrm{E}$. X 20 .

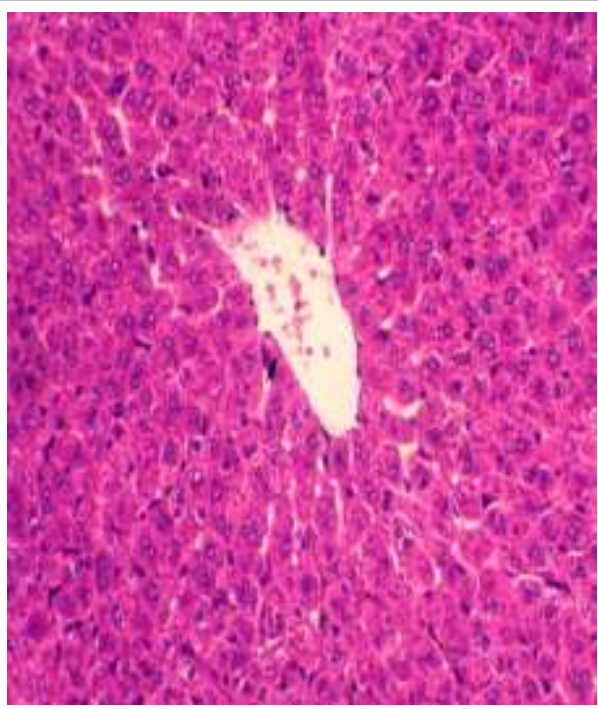

Fig. (6): Garlic received group, the liver showing normal lobular architecture with central vein and radiating hepatic cell cords. H\&E. X 20.

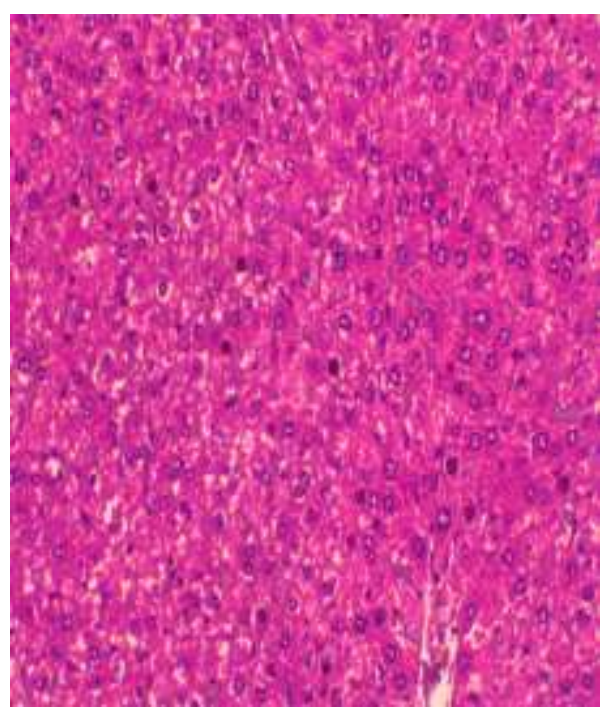

Fig. (8): Ginger and garlic received group, the liver showing mild hydropic degeneration of the hepatocytes. H\&E. $\mathrm{X} 20$.

$\overline{\text { Kafrelsheikh Vet. Med. J. Vol. } 12 \text { No. } 2 \text { (2014) }}$ 


\section{DISCUSSION}

The liver is an important organ which is actively involved in many metabolic functions. Hepatic damage is associated with distortion of these metabolic functions (El Shemy et al., 2011).

Our result revealed that, significant increase GGT, AST, ALT in CCL4 control group . in which CCL4 is a common hepatotoxin( Shenoy et al.,2001), by stimulation of lipid peroxidation and production of free radicals ( Basu,2003). Our finding is consistent with perivous studies that reported that, AST, ALT and GGT were increased response to CCL4 treatment ( Hanaa et al., 2012)

Our result revealed that, significant decrease ALT, AST if compared with CCL4 treated control group, this finding is convenient with the previous studies, effect of ginger may due to ginger has antioxidant activity. this result consistent with Yemitan and Izegbu (2006) and Ajith et al., (2007) which reported that, ginger extract or its constituents has antioxidant properities and so improve the liver dysfunctions and hepatic damage that induced by CCL4 and acetaminophen.

Our result showed that, significant dercrease the GGT level in ginger treatment group if compared with CCL4 control group, this finding consistent with Hanaa et al., (2012) which documented that GGT significantly decrease response to ginger extract treatment.

Our result revealed that, orally administration of garlic can ameliorate the high level of serum ALT, AST, GGT and may reach to the normal level. our finding harmonious with Pradeep et al., (2007) which reported that, administration of garlic induce significantly reduce the 
liver enzymes activity in hepatotoxicity induced rats . due to its ability to reduce free radical-induced oxidative damage in the liver (Gedik et al., 2005).Indeed, our result revealed that, the ginger has more potent effect on lower the serum ALT, AST, GGT, than garlic.

Liver damage was examined by histopathological studies, in which there are many pathological changes in $\mathrm{CCl}_{4}$ control liver rats such as focal fatty changes, focal central sinusoid cell dilation, and hydropic degeneration in addition to previously mentioned result, our finding harmonious with Krishnan and Muthukrishnan (2012) which reported that, $\mathrm{CCl}_{4}$ induce extensive necrosis of hepatocytes in centrilobular regions of liver. $\mathrm{CCl}_{4}$ induce centrilobular congestion with inflammatory cells infiltration of inflammatory cells, extensive fatty changes and sever centrilobular necrosis (Tsutomu et al., 2010).

The pathological changes may due to carbon tetrachloride, its metabolites and trichloromethyl radical activated radicals bind to micro molecules and reduce lipids peroxidative degeneration of polyunsaturated fatty acids (Adefolaju et al., 2009), so lead to lipid peroxides formation that turn give products like malonylaldehyde that cause damage to membrane (Ulicna et al., 2003). This lipid peroxidative degradation of biomembranes is one of the main causes of hepatotoxicity by carbon tetrachloride.

Our results revealed that, ginger treatment can ameliorate most of hepatic pathological changes caused by carbon tetrachloride, nearly treated most of hepatic pathological lesion and keep normal liver architecture, our findings convenient with (Mohamed Atif and Ahmed, 2013) which reported that, adriamycin combined with ginger treatment are return the mitochondria nearly to normal, partial disappearance of hepatic damage, degeneration and necrosis were decreased $62 \%$ when 
combined with ginger.so ginger play a key role in the attenuation of hepatic injury, preserve the structural integrity of the hepatocellular structures and has anti-fibrotic agent. Ginger treatment can reduce the deposition of collagen fiber about $64 \%$ if compared with non-treated one (Wasser et al., 1998; Jia et al., 2001 and Fu et al., 2008).

Our study revealed that, garlic treatment can ameliorate the pathological changes that produce by $\mathrm{CCl}_{4}$ and morphology of the liver that appear almost normal except very mild focal hydropic degeneration , very mild congestion, mild sinusoid dilation and completely removal of fatty changes that observed in the liver of $\mathrm{CCl}_{4}$ control group . our findings are consistent with Yetunde and James (2012); Attalla et al., (2012) Patrick et al., (2007); Adedayo et al., (2013) and Abd and Baghdadi, (2009) which reported that, treatment with the garlic oil reduce morphological changes produced by $\mathrm{CCl}_{4}$ and greatly reverted the microanatomy of the liver, this may due to garlic oil contain on certain compounds such as germanium and selenium that play an important role in normalizing the oxygen utilization in the cells (Hussein et al., 2007).

Our result, showed that the combination garlic and ginger also improve the fatty degeneration and return the liver architecture nearly to normal state. Finally, the histopathological studies demonstrated that, ginger and garlic possess a potent hepatoprotective activity.

In conclusion, this study document that, ginger and garlic is antioxidant and anti-inflammatory activity, using garlic and ginger are useful for prevention and treatment of liver injury, so this study highlighted on the therapeutic value of ginger and garlic. So other studies are needed to investigate the their role in other inflammatory diseases and study a new mechanism. 


\section{REFERENCES}

- Abd A. J. and Al-Baghdadi R. J. T.(2009): "Effects of Garlic Oil in Correction of Hepatotoxicity Induced by CCl4 in Rabbits". Al- Anbar J. Vet. Sci., 2(2)

- Adedayo O Ademiluyi, Ganiyu Oboh, Tosin R Owoloye, Oluwaseun J Agbebi (2013): "Modulatory effects of dietary inclusion of garlic (Allium sativum) on gentamycin-induced hepatotoxicity and oxidative stress in rats". Asian Pacific Journal of Tropical Biomedicine ., 3(6): 470-475.

- Adefolaju, G. A.; Ajao, M. S.; Olatunji, L. A.; Enaibe, B. U. \& Musa, M. G. (2009): "Hepatoprotective Effect of Aqueous Extract of Water Leaf ( Talinum Triangulare ) on Carbon tetrachloride (CCl4) Induced Liver Damage in Wistar Rats". The Int. J. of Pathol., 8 (1): 205- 215.

- Adejoke Yetunde and Olakunle James (2012) : "Histological and biochemical study of the effects of garlic oil and vitamin $\mathrm{E}$ in paracetamol induced hepatotoxicity". International Journal of Pharmacy and Pharmacology., 1(2): 012-018.

- Ajith, T.A., Hema, U. and Aswathy, M.S. (2007): "Zingiber officinale Roscoe prevents acetaminophen-induced acute hepatotoxicity by enhancing hepatic antioxidant status". Food Chem. Toxicol., 45, 2267-2272. 
- Attalla Farag El-Kott, Ayman M. Abdel-Aziz, Abd El-Karim M. Abd El-Latif, Ezz Mohie El-Gamal and Abdalla Mohamed Khalil (2012): "Amelioration of Nitrate-induced Hepatotoxicity by Allium sativum in Mice”. Journal of Medical Sciences., 12: 85-91.

- Basu, S., (2003): "Carbon tetrachloride-induced liper peroxidation: eicosanoid formation and their regulation by antioxidant nutrients". Toxicology., 189: 113-127.

- Borrelli F, Capasso R, and Izzo AA (2007): "Garlic (Allium sativum L.): Adverse effects and drug interactions in humans". Mol. Nutr. Food Res., 51: 1386-1397.

- El Shemy, M.A.a, Abdalla, A.O.b, and Fararh, K.M.a (2011): "Antioxidant and hepatoprotective effects of ginger in rats". Benha veterinary medical journal, 22(2): 7-14

- Fu Y, Zheng S, Lin J, Ryerse J,and Chen A. (2008): "Curcumin protects the rat liver from CCl4-caused injury and fibrogenesis by attenuating oxidative stress and suppressing inflammation". Mol Pharmacol., 73(2): 399-409.

- Gedik N, Kabasakal L, Sehirli O.et al. (2005): "Long-term administration of aqueous garlic extract (AGE) alleviates liver fibrosis and oxidative damage induced by biliary obstruction in rats". Life Sci., 76:2593-606

- Ha KT, Yoon SJ, Choi DY, Kim DW, Kim JK, and Kim CH, J. (2005): "Ethnopharmacol, 96,529-535. Recknagel RO, Glende EA, Dolak JA and Waller RL: Mechanisms of carbon tetrachloride toxicity". Pharmacol Ther 43: 139 - 154 
- Hanaa Wafay, Gamila El-Saeed, Safinaz El-Toukhy, Eman Youness, Nabila Ellaithy, Mervat Agaibi and Shereen Eldaly (2012) : "Potential Effect Of Garlic Oil and Silymarin on Carbon Tetrachloride-Induced Liver Injury". Australian Journal of Basic and Applied Sciences., 6(3): 409-414

- Hussein, J. S.; Oraby, F. S. and El-Shafey, N. (2007): "Antihepatotoxic effect of garlic and onion oils on ethanol-induced liver injury in rats”. J. Applied Sciences Research., 3(11): 1527-1533.

- Jain A, Singhai AK. (2010): "Effect of Momordica dioica Roxb on gentamicin model of acute renal failure". Nat Prod Res., 20: 13791389.

- Jia JD, Bauer M, Cho JJ, Ruehl M, Milani S, Boigk G, Riecken EO, and Schuppan D. (2001): "Anti-fibrotic effect of silymarin in rat secondary biliary fibrosis is mediated by down regulation of procollagen alpha1(I) and TIMP-1”. J Hepatol., 35:392-8.

- Kazeem, M.I., Bankole, H.A. and Fatai, A.A. (2011): "Protective effect of ginger in normal and carbon-tetrachloride induced hepatotoxic rats". Annals of Biological Research., 2(1): 1-8.

- Krishnan Nandhini, and Muthukrishnan Suriyavathana (2012): "Effect of Nigella sativa seed extract on carbon tetrachloride-induced hepatotoxicity in rats". Journal of Acute Medicine 2(4): 107-113. 
- Mohamed Atif and Ahmed Said Ahmed (2013): "The Protective Effect of Ginger (Zingiber Officinale) Against Adriamycin- Induced Hepatotoxicity in Rats: Histological Study". Life Science Journal., $10(1)$

- Patrick-Iwuanyanwu K. C., Wegwu M. O. and Ayalogu E. O., (2007): "The Protective Nature of Garlic, Ginger and Vitamin E on CCl4-Induced Hepatotoxicity in Rats". Asian Journal of Biochemistry, 2: 409-414.

- Pradeep K, Mohan CV, Gobianand K. et al. (2007): "Silymarin modulates the oxidant-antioxidant imbalance during diethylnitrosamine induced oxidative stress in rats". Eur J Pharmacol., 560:110-6

- Reitman, A, and Frankel, S. (1957): " Colorimetric method for A colorimetric method for the determination of serum glutamic oxalacetic and glutamic pyruvic". Amer J. Clin. Path., 28:56.

- Shenoy, K.A., S.N. Somayaji and K.L. Bairy (2001): "Hepatoprotective effects of ginkgo biloba against carbon tetrachloride induced hepatic injury in rats". Indian J. Phamacol., 33: 260-266.

- Tsutomu Fujii, Bryan C Fuchs, Suguru Yamada, Gregory Y Lauwers, Yakup Kulu, Jonathan M Goodwin, Michael Lanuti and Kenneth K Tanabe. (2010): "Carbon tetrachloride induced liver fibrosis: Histopathological changes and expression of CD133 and epidermal growth factor”. BMC Gastroenterology., 10:79 . 
- Ulicna, O.; Greskshek, M.; Vancovao, O.; Zlator, I. \& Bocek, P. (2003): "Hepatoprotective effect of Rooibos tea (Aspalathus linearis) on CCl4 induced liver damage". Physiol. Res., 52: 461-466.

- Wasser S, Ho JMS, Ang HK, and Tan CEL. (1998): "Salvia miltiorrhiza reduced experimentally-induced hepatic fibrosis in rats". J Hepatol., 29:760-71.

- Yemitan OK, and Izegbu MC (2006): "Protective effects of Zingiber offcinale (zingiberaceae) against carbon tetrachloride and acetaminophen- induced hepatotoxucity in rats". Phytother. Res., 20(11): 997-1002.

- Yetunde Adejoke and James Olakunle (2012): "Histological and biochemical study of the effects of garlic oil and vitamin $E$ in paracetamol induced hepatotoxicity". International Journal of Pharmacy and Pharmacology., 1(2):012-018. 